\title{
The effect of silicon on the nanoprecipitation of cementite
}

\author{
B. Kim ${ }^{1}$, C. Celada ${ }^{2}$, D. San Martín², T. Sourmail ${ }^{3}$, P.E.J. Rivera-Díaz-del-Castillo ${ }^{1}$ \\ ${ }^{1}$ Department of Materials Science and Metallurgy, University of Cambridge, Pembroke \\ Street, CB2 3QZ, UK \\ ${ }^{2}$ MATERALIA Group, Department of Physical Metallurgy, Centro Nacional de \\ Investigaciones Metalúrgicas (CENIM-CSIC), Av. Gregorio del Amo 8, 28040 Madrid, Spain \\ ${ }^{3}$ ASCOmetal-CREAS (research centre) Metallurgy, BP 7004557301 Hagondange Cedex, \\ France
}

\begin{abstract}
The current work presents a comprehensive study that aims at understanding the role of silicon on $\theta$ precipitation, as well as on the $\varepsilon \rightarrow \theta$ carbide transition in tempered martensite. Cementite nucleation was modelled under paraequilibrium conditions in order to ensure silicon's presence in the carbide, where both thermodynamic and misfit strain energies were calculated to evaluate the overall free energy change. The growth stage was investigated using in situ synchrotron radiation; three alloys containing a wide range of silicon contents have been studied. Silicon appears to play a significant role on carbide growth. It was observed throughout tempering that as silicon content increased in the alloy, cementite precipitation was slower. Literature reports that cementite growth is accompanied by silicon partitioning, where the silicon content inside the carbide decreases as tempering progresses. Therefore it appears that the limiting factor of the growth kinetics is the rate at which silicon is being rejected from the carbide, which piles up at the carbide/matrix interface, acting as a barrier for further growth.
\end{abstract}

Keywords: Phase transformation; Synchrotron radiation; Carbides; Precipitation kinetics; Tempered martensite 


\section{Introduction}

It is a well-established fact that silicon plays a retarding effect on the epsilon to cementite carbide transition in tempered martensitic steels $[1,2]$. This concept has attracted considerable industrial interest in the optimisation of alloying in steels $[2,1,3,4,5,6,7$, 8]. The retention of the $\varepsilon$ carbide phase leads to ultra-high strength in steels, a property attributed to the presence of microstrains at the precipitate/matrix interface [9]. Consequently, near the $\varepsilon \rightarrow \theta$ regime softening takes place, where ductility is recovered at the expense of loss in strength. Being of considerable interest from both the academic and industrial point of view, the role of silicon during tempering has been studied extensively over the past decades. This project's initial interest was in the development of ultra-high strength steels for spring steels applications. By understanding the carbide transition at the microstructural level, alloy tailoring can be achieved, where improved mechanical properties allow for greater flexibility in designing structural components.

The general understanding has been that the $\varepsilon \rightarrow \theta$ transition, also known as the third stage of tempering, takes place in two steps: Stage IIIA, where the remaining carbon atoms within the matrix are taken up for cementite precipitation while $\varepsilon$-carbide persists in the matrix. At Stage IIIB it has been thought that once the matrix becomes depleted, the $\varepsilon$-carbide decomposes in order to assist in the further production of cementite. The kinetics were related to the diffusion of carbon through low-carbon martensite in Stage IIIA, and to the mobility of substitutional elements or the self-diffusion of Fe in Stage IIIB. The addition of silicon would merge the steps IIIA and IIIB, and shift the reactions to higher temperatures, consequently stabilising $\varepsilon$ at higher temperatures $[5]$.

One of the earlier findings relating silicon with cementite showed that during tempering the ratio of Si:Fe within iron carbide decreased throughout the epsilon to cementite transition [9]. This demands the partitioning of silicon during $\varepsilon \rightarrow \theta$ transition and 
growth. Evidence of the latter case has been widely reported $[1,3,10,11]$ by means of three dimensional atom probe (3DAP) where the kinetics of carbide growth has been studied.

Due to the absence of the metastable $\varepsilon$-carbide phase in commercial thermochemical databases, most of the computational thermodynamic work has been on the formation of cementite from martensite under both ortho- and para-equilibrium conditions $[12,13]$. Contrary to experimental evidence, thermodynamic modelling by Kozeschnik and Bhadeshia [13] showed that having silicon in an iron-lattice does not necessarily delay the formation of cementite from ferrite, and this effect only becomes appreciable at low carbon contents. The Density Functional Theory (DFT) work by Jang et al. [14] showed that when silicon is substituted in an Fe-lattice, it is more energetically favourable to precipitate $\theta$ rather than $\varepsilon$. Based on the experimental evidence provided in literature, thermodynamic data appear to be rather counterintuitive.

On the overall $\varepsilon \rightarrow \theta$ transition, the question at hand has typically been addressed from both thermodynamic and kinetic standpoints. However, recently the misfit energy between carbide and matrix was seen to play a crucial role in precipitation [15]. Furthermore, Jang [14] et al. hinted that the effect of silicon on stabilising $\varepsilon$ is not a thermodynamic effect, but a coherency effect instead, as the incorporation of silicon would lead to a higher coherency at the carbide/matrix interface.

Incorporating both thermodynamic and misfit factors, this work further elaborates on the results presented by the authors [16] in order to model the aforementioned carbide transition. The model developed could potentially be used in order to understand the thermokinetic aspects of the phase transformation occurring in tempered martensite.

Following nucleation, the next aspect to be considered is growth kinetics of cementite. Faced with the limitations of using conventional laboratory X-ray equipment 
in detecting carbide phases, trial runs on the I11 beamline at Diamond Light Source [17] showed promising results. Having succeeded in resolving carbide peaks, in situ experiments were designed to examine the effect of silicon in carbide evolution during martensite tempering. The use of high energy X-ray diffraction from synchrotron sources is a technique that has been very effective in understanding mechanisms at atomic and microstructural levels. In steels, cases ranging from martensite decomposition $[18,19]$ to carbide characterisation $[20,21]$ have been explored for decades. The wealth of information that can potentially be extracted from the synchrotron, coupled with the previous model [16] combined with the gathered knowledge from literature, will allow further insight in understanding the role of silicon on the nucleation and growth of cementite. The cementite nucleation model is presented in Section 3, followed by the experimental work carired out at the synchrotron facility in Section 4. The $\varepsilon \rightarrow \theta$ transformation kinetics is interpreted in Section 5, and Section 6 presents the conclusions.

\section{Alloy selection}

Initial work was carried out on an experimental cast (referred to as 'Model Alloy' in this article); the preparation details have been described elsewhere [16]. In addition to the model alloy, two more alloys with compositions similar to industrial ones containing different silicon contents have been studied, Table 1.

These were casts made specifically for this study, where laboratory heats were manufactured as $20 \mathrm{~kg}$ ingots using a vacuum induction furnace. The ingots, of section 100 $\times 100 \mathrm{~mm}$, were left to cool to room temperature. Approximately 2/10 and 1/10 of the total material was cut from the top and bottom of the ingot respectively, keeping 
the more homogeneous and sound material from the remaining $7 / 10$. This was then homogenised at $1200{ }^{\circ} \mathrm{C}$, and forged into a bar of $40 \mathrm{~mm}$ diameter. To reduce hardness and to ease cutting, the bars thus forged were slowly cooled in a furnace rather than in air. The as-received material consisted of a pearlitic microstructure with an initial hardness of $328 \pm 3$ and $311 \pm 4 \mathrm{HV} 1$ for alloys A and B, respectively.

Table 1: List of alloys and their chemical compositions (in weight \%, Fe to balance).

\begin{tabular}{ccccccccc}
\hline & $\mathrm{C}$ & $\mathrm{Si}$ & $\mathrm{Mn}$ & $\mathrm{Cr}$ & $\mathrm{Ni}$ & $\mathrm{Cu}$ & $\mathrm{V}$ & $(\mathrm{Mo}, \mathrm{Ti})$ \\
\hline Model & 0.50 & 2.03 & - & - & - & - & - & - \\
Alloy A & 0.56 & 2.30 & 0.69 & 0.89 & 0.204 & 0.147 & 0.103 & $\leq 0.05$ \\
Alloy B & 0.53 & 1.43 & 0.72 & 0.91 & 0.205 & 0.156 & 0.101 & $\leq 0.05$ \\
\hline
\end{tabular}

\section{Modelling cementite nucleation}

The process of cementite nucleation during martensite tempering still remains unclear. For instance, Nam et al. [22] reported a carbide precipitation mechanism similar to the one described by Gordine and Codd [5], where a likely place for cementite nucleation would be at the matrix/epsilon interface. This observation would imply that $\varepsilon$ - and $\theta$ nucleation is a two-step process. However Perez and Deschamps [23] based their work on the postulate that both carbides nucleate at the same time, independent of each other, but due to competitive precipitation kinetics, the metastable $\varepsilon$-carbide grows first. Once it loses stability, it would dissolve to allow $\theta$ grow. This work aims to gain a further understanding on the nature of the cementite precipitation process.

Typically in the case of homogeneous nucleation the overall free energy change, $\Delta G$, 
is defined as:

$$
\Delta G=-V\left(\Delta G_{V}-\Delta G_{S}\right)+A \gamma
$$

where $G_{V}, G_{S}$ and $\gamma$ are the chemical, strain and interfacial energy terms for the newly forming phase of volume $V$ and area $A$.

The earlier work presented by the authors [16] was based on the assumption that the effective driving force for an already existing particle embedded within a matrix phase is a function of the chemical free energy and the misfit strain energy [24]. Considering carbide precipitation during martensite tempering, the $G_{V}$ term is the driving force that favours the precipitation reaction. However, owing to the matrix/precipitate mismatch at the interface, $G_{S}$ will counterbalance the chemical driving force. Therefore only when the chemical driving force is sufficiently large, carbide formation is favoured, i.e. when $\left|G_{V}\right|>\left|G_{S}\right|$. Hence, a simplified expression of the effective driving force can be found: $\mathrm{DF}=G_{V}-G_{S}$.

The values for $G_{V}$ and $G_{S}$ are evaluated in sections 3.1 and 3.2 respectively.

\subsection{Thermodynamics}

At the early stages of carbide precipitation during martensite tempering (generally temperatures below $350{ }^{\circ} \mathrm{C}$ ), the diffusivity of most elements is substantially low. The only elements that will be able to diffuse significantly are interstitials such as carbon. Therefore paraequilibrium conditions need to be considered.

Consider a carbide/matrix interface: due to the relatively high mobility of carbon, the chemical potentitial of carbon, $\mu_{C}$, will have equilibriated in a short time, i.e. $\mu_{C}^{P E-\alpha}=\mu_{C}^{P E-\theta}$. On the other hand, Fe and the other substitional elements would have

different chemical potentials [25], i.e. $\mu_{X}^{P E-\alpha} \neq \mu_{X}^{P E-\theta}$, where given their restricted diffusivities, $X$ is used to collectively refer Fe and the other substitutional elements. 
The driving force for nucleation, $\Delta G^{N}$ of paraequilibrium cementite is given by [12]:

$$
\Delta G^{N}=\left(\mu_{X}^{N, P E-\theta}-\mu_{X}^{N, P E-\alpha}\right) x_{X}^{N, P E-\theta}+\left(\mu_{C}^{N, P E-\theta}-\mu_{C}^{N, P E-\alpha}\right) x_{C}^{N, P E-\theta}
$$

where $x_{i}^{N, P E-\phi}$ is the mole fraction of element $i$ within phase $\phi$.

Furthermore, since paraequilibrium cementite inherits the matrix composition, the concentration of the elements will be the same across the interface, thus the $u$-fraction is considered, which is defined as [25]:

$$
u_{i}=\frac{x_{i}}{\sum x_{X}}
$$

where $x_{i}$ is the mole fraction of element $i$, and $\sum x_{X}$ is the sum taken for Fe and the other substituional elements. In order to achieve paraequilibrium conditions at the interface, the product of chemical potentitial $\mu_{Z}$ and $u_{Z}$ must be the same in both phases.

Having defined the alloy system and conditions, the $u$-fraction was determined in order to calculate the paraequilibrium driving force. The TCFE6 (v 6.2) database [26] was used in ThermoCalc to obtain the $\Delta G^{N}$ term. Once obtained, the volume Gibbs free energy can be determined by:

$$
\Delta G_{V}=\frac{\Delta G^{N}}{V_{m, \theta}}
$$

where $\Delta G^{N}$ is the chemical Gibbs free energy obtained from ThermoCalc expressed in $\mathrm{J} \mathrm{mol}{ }^{-1}$, and $V_{m, \theta}$ is the molar volume of cementite, $5.84 \times 10^{-6} \mathrm{~m}^{3} \mathrm{~mol}^{-1}$ using the lattice parameters from [27]. The $\Delta G^{N}$ values are summarised in Figure 1. 


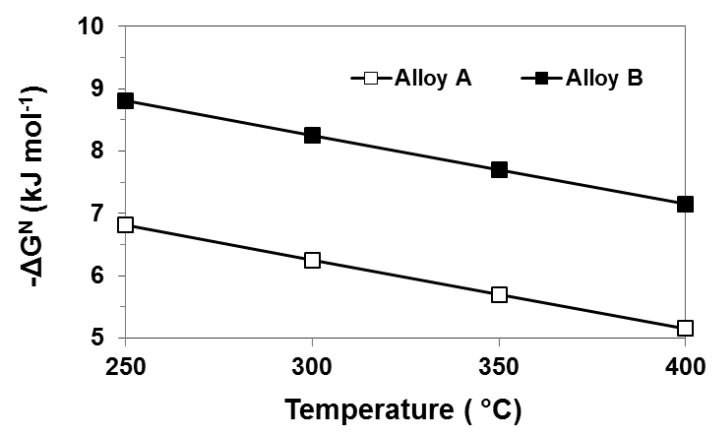

Figure 1: Driving force for cementite nucleation, $\Delta \mathrm{G}^{\alpha \rightarrow \alpha+\theta}$ under paraequilibrium conditions shown for all three alloys.

The obtained values for the driving force are comparable with the values that are found in literature $[12,28,13]$. Seen in Figure 1, the chemical driving force for Alloy A is smaller than that for Alloy B. Hence, driving force for cementite nucleation under paraequilibrium conditions decreases as silicon content increases. The second aspect to evaluate is the misfit at the matrix/carbide interface.

\subsection{Misfit}

The elastic strain energy stored in the matrix surrounding an inclusion is approximated by $[29]$ :

$$
\Delta G_{S}=6 \mu \delta^{2} \cdot E\left(\frac{c}{a}\right),
$$

where $\mu$ is the matrix shear modulus, $\delta$ is the volumetric misfit and the $E$ term accounts for the shape factor of the inclusion, where $a$ is the equitorial diameter and $c$ is the polar diameter. The misfit is a function of the lattice parameters:

$$
\delta=\frac{1}{3}\left(\frac{V_{1}-V_{2}}{V_{2}}\right)
$$


where $V$ refers to the atomic volumes for phases 1 and 2 . The lattice parameter of

ferrite, $a_{\alpha, 0}$ (in $\mathrm{nm}$ ), can be estimated empirically by the concentration of each element in atomic percent [30]:

$$
a_{\alpha, 0}=0.28664+0.00006(M n)-0.00003(S i)-0.00005(C r)
$$

Since carbide precipitation occurs at temperatures above ambient, temperature dependency of the shear modulus and the lattice parameters should be considered. Those will be explored in 3.2.1 and 3.2.2 respectively.

\subsubsection{Shear modulus}

The temperature dependency of the shear modulus has been extracted from [31], for a similar alloy range (Fe-0.4C-0.14Si-0.86Mn wt.\%). The values extracted are listed in Table 2.

Table 2: Matrix shear modulus variation as a function of temperature.

\begin{tabular}{cccccc}
$\mathrm{T}\left({ }^{\circ} \mathrm{C}\right)$ & 25 & 250 & 300 & 350 & 400 \\
\hline$\mu(\mathrm{GPa})$ & 81 & 75 & 73 & 71 & 68.5 \\
\hline
\end{tabular}

These values are to be substituted into (5) in order to obtain more accurate values of the strain energies during actual tempering conditions.

\subsubsection{Lattice parameters}

Having determined $a_{\alpha, 0}$ using (7), temperature should be incorporated in the following manner [32]:

$$
a_{\alpha}=a_{\alpha, 0}[1+\beta(T-300)]
$$


where $\beta$ is the linear expansion coefficient and $T$ is the absolute temperature The value of $\beta$ was reported to be $17.5 \times 10^{-6}$ for ferrite containing up to 0.6 wt. $\%$ carbon [32] (NB. although these reported values were determined for a temperature range between 527 and $927^{\circ} \mathrm{C}$, they will still be used given the similar carbon contents in the matrix).

Furthermore, at the early stages of tempering, the tetragonality of the matrix phase also needs to be considered. Previous XRD measurements on the Model Alloy tempered at $250{ }^{\circ} \mathrm{C}$ revealed the following: $\mathrm{a}_{\alpha}=0.2862$ and $\mathrm{c}_{\alpha}=0.2876 \mathrm{~nm}(\mathrm{c} / \mathrm{a}=1.005)[16]$. Given the similar carbon content in the three alloys, the tetragonality of $\alpha$ ' is assumed to be 1.005 at $250{ }^{\circ} \mathrm{C}$ for alloys $\mathrm{A}$ and $\mathrm{B}$. However, throughout tempering at higher temperatures, as carbide precipitation occurs the carbon content in the matrix would reduce, decreasing the tetragonality of the matrix to 1, i.e. it becomes cubic. Therefore from $300{ }^{\circ} \mathrm{C}$ onwards the matrix is assumed to be cubic. The list of variables used for the misfit computation are summarised in Table 3.

Table 3: List of variables used for misfit computation of the matrix phase. The last 3 columns correspond to the atomic volumes of the matrix phase (units in $\times 1000 \mathrm{~nm}^{3}$ ).

\begin{tabular}{ccccc}
\hline Temperature $\left({ }^{\circ} \mathrm{C}\right)$ & Tetragonality & Alloy A & Model alloy & Alloy B \\
\hline 250 & 1.005 & 11.82 & 11.88 & 11.98 \\
300 & 1 & 11.79 & 11.85 & 11.95 \\
350 & 1 & 11.82 & 11.88 & 11.98 \\
400 & 1 & 11.85 & 11.92 & 12.01 \\
\hline
\end{tabular}

Although strictly speaking the lattice parameters of the carbide phases would also change due to thermal expansion, a constant value has been used for their atomic volume. Values for $250{ }^{\circ} \mathrm{C}$ are summarised in Table 4 . 
Table 4: The misfit between the different phases, $(\times 100)$

\begin{tabular}{cccc}
\hline Interface considered & $\alpha^{\prime} / \varepsilon$ & $\alpha^{\prime} / \theta$ & $\varepsilon / \theta$ \\
\hline Alloy A & 4.6 & 6.4 & 2.2 \\
Model & 5.0 & 6.8 & 2.2 \\
Alloy B & 4.8 & 6.6 & 2.2 \\
\hline
\end{tabular}

Nucleation of cementite has been suggested to take place at the matrix-epsilon interface [8]. Closer inspection of Table 4 shows that the sum of $\delta\left(\alpha^{\prime} / \varepsilon\right)$ plus $\delta(\varepsilon / \theta)$ roughly adds up to that of $\delta\left(\alpha^{\prime} / \theta\right)$. This could be a way of understanding the role of a metastable phase, as the transitional phase offers an intermediate misfit energy path.

Temperature and composition effects for the matrix have been assessed, which would allow a more precise computation of the $G_{s}$ term.

\subsection{Interfacial energy}

The differences such as crystal structure and compositions determine the nature of the interface between two adjoining phases. There are three general categories of interfaces: coherent, semicoherent and incoherent [24]. As coherency is lost across the interface, the interfacial energy, $\gamma$, increases. Typically it has been stated that for coherent interfaces, $\gamma$ can be as low as $1 \mathrm{~mJ} \mathrm{~m}^{-2}$ and can go up to $200 \mathrm{~mJ} \mathrm{~m}^{-2}$. In semicoherent interfaces, $\gamma$ is in the range of $200-500 \mathrm{~mJ} \mathrm{~m}^{-2}$, the strain caused by the loss in coherency is replaced by misfit dislocations. Incohrent interfaces are characterised by high $\gamma$, in the $500-1000 \mathrm{~mJ} \mathrm{~m}^{-2}$ range.

Perez and Deschamps [23] reported the interfacial energy of $\varepsilon$ and $\theta$ for the nucleation process based on the Becker-Döring theory: $\gamma\left(\alpha^{\prime} / \varepsilon\right)=0.147 \mathrm{~J} \mathrm{~m}^{-2}$ and $\gamma\left(\alpha^{\prime} / \theta\right)=0.174$ $\mathrm{J} \mathrm{m}^{-2}$.

Nevertheless if one were to consider that the $\varepsilon \rightarrow \theta$ transition is a two-step process, 
where the intralath cementite was suggested to nucleate at the $\alpha / \varepsilon$ boundary [8], in order to successfully model the interfacial energy there are three interfaces to be considered: $\varepsilon / \alpha^{\prime}, \varepsilon / \theta$ and $\theta / \alpha^{\prime}$. By the time carbide transition takes place, $\varepsilon$ would have reached a considerable size. It is known that the coherency between a precipitate and the matrix decreases as the former grows, subsequently increasing the interfacial energy. Supposing that a semicoherent interface exists between the matrix and $\varepsilon$ prior to $\theta$ nucleation, then $\gamma\left(\alpha^{\prime} / \varepsilon\right)_{\text {semicoherent }}>\gamma\left(\alpha^{\prime} / \theta\right)_{\text {coherent }}$. Thus during the $\varepsilon$ to $\theta$ transition, the formation of the new interfaces given by the sum of $\gamma(\varepsilon / \theta)_{\text {coherent }}$ plus $\gamma\left(\alpha^{\prime} / \theta\right)_{\text {coherent }}$ might counterbalance the annihilation of the existing interface $\gamma\left(\alpha^{\prime} / \varepsilon\right)_{\text {semicoherent }}$.

\subsection{Computing the driving force}

Now that $G_{V}$ and $G_{S}$ have been determined, the effective driving force can be competed, as shown in Figure 2 for $\theta$-nucleation.

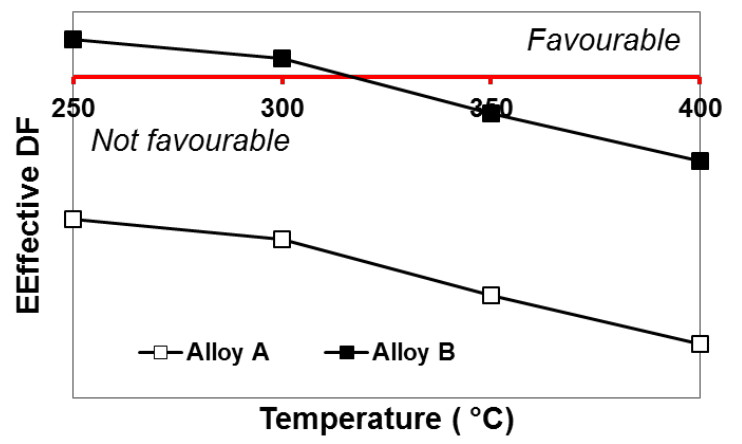

Figure 2: Driving force for cementite nucleation, $\Delta G^{\alpha \rightarrow \alpha+\theta}$ under paraequilibrium conditions.

One aspect to notice is that in the presence of defects, an extra energy term needs to be considered. Thus, (1) becomes:

$$
\Delta G=-V\left(\Delta G_{V}-\Delta G_{S}\right)+A \gamma-\Delta G_{d}
$$


where the $\Delta G_{d}$ term accounts for the reduction in the nucleation energy barrier owing to the presence of defects in the material.

Andrews reported the formation of cementite at $250{ }^{\circ} \mathrm{C}$ [33], where it becomes apparent that cementite nucleation is strongly related to twin density [34]. Furthermore, on the Fe-C-Si model alloy system, cementite was seen present near twin regions at 250 ${ }^{\circ} \mathrm{C}$ [16]. Thus, incorporating the presence of defects, the horizontal axis (marked red in Figure 2 is likely to shift down, facilitating the nucleation of $\theta$ at higher silicon contents. Although it appears that intralath carbide precipitation is a two-step process, where epsilon first precipitates followed by cementite, it is also true that in the presence of defects the nucleation barrier can be sufficiently lowered in order to allow earlier cementite nucleation.

\section{Synchrotron experiments}

Synchrotron experiments were carried out at the I11 beamline (high resolution powder diffraction) [17] of Diamond Light Source (Didcot, UK). In order to carry out in situ tempering, thin round needles of approximately $0.5 \mathrm{~mm}$ diameter and $6 \mathrm{~mm}$ length were studied under transmission during continuous heating using a Cyberstar hot-air blower provided by the beamline. The sample was mounted at the tip of a brass holder and fixed with phenol-aldehyde epoxy resin. Once the resin was cured, the sample was then loaded on the spinner, and aligned with the incoming beam using the sample alignment cameras. A $15 \mathrm{keV}$ beam energy $(\lambda \approx 0.826162 \AA)$ was used.

Test runs were carried out at the start of the beamtime in order to determine the optimum conditions for tempering. Due to time constraints, and also because temperature control of the hot-air blower is less precise below $250^{\circ} \mathrm{C}$, the heat treatment was carried out starting from $300{ }^{\circ} \mathrm{C}$. Moreover it was also found that a significant 
temperature gradient existed between the nozzle and the sample. Although it is not possible to state the carbide transition temperature with absolute certainty, the relative transition temperatures can be estimated. While the furnace was set at $300{ }^{\circ} \mathrm{C}$, and the sample had been aligned, the hot-air blower was brought to the heating position. To ensure temperature homogeneity, the sample was isothermally held for 10 minutes before ramping up the temperature from 300 to $900{ }^{\circ} \mathrm{C}$ at a rate of $0.1^{\circ} \mathrm{C} / \mathrm{s}$. Due to the nature of this work, a time-resolved PSD detector [35] was used in order to take rapid scans continuously throughout tempering, giving an exposure time of 60 seconds in total for each scan. It is worth noting that between the start and end of one scan, the temperature of the nozzle would have increased by approximately $6{ }^{\circ} \mathrm{C}$. Two runs were made for each in situ condition to ensure reproducibility. Additional to the in situ samples, reference dilatometry specimens for alloys A and B were also prepared for benchmark purposes.

\subsection{Sample preparation}

Synchrotron reference samples were heat treated using a high precision furnace of an Adamel Lhomargy DT1000 high resolution dilatometer. These were austenitised at $880{ }^{\circ} \mathrm{C}$ for 180 seconds, quenched using a helium flux at velocities near $300-500{ }^{\circ} \mathrm{C}$ per second. Subsequent tempering was carried out at 250, 300, 350, 400, 450 and $500{ }^{\circ} \mathrm{C}$ for 1800 seconds.

For the in situ synchrotron samples, austenitisation was carried out in laboratory furnaces at $880{ }^{\circ} \mathrm{C}$ and quenched in ice brine, four days prior to beamtime. In order to minimise decarburisation during austenitisation, the needles were carefully wrapped in stainless steel foil. Each wrap contained 4 needles, where 3 were saved for synchrotron measurements and the remaining one was used for characterisation. The as-quenched samples were carefully stored in membrane boxes. 
Additional to the needle geometries, flat-plate specimens of $20 \times 20 \mathrm{~mm}^{2}$ with a thickness of $\sim 1 \mathrm{~mm}$ were prepared for conventional XRD measurements on the asquenched condition. Austenitisation and quenching was carried out using the same procedure as the needle samples.

\subsection{Preliminary characterisation}

In order to ensure that a martensitic microstructure has been obtained during quenching, the as-quenched condition of flat-plate specimens was investigated by conventional XRD methods prior beamtime. A Phillips X'Pert PW3020 model equipped with a cop-

per radiation source $(\lambda \approx 1.540598 \AA)$. Scans were taken from 40 to $105^{\circ} 2 \vartheta$, using a step size of $0.035^{\circ}$ and a dwell time of 15 seconds. Diffraction analyses and Rietveld refinement were carried out using HighScore Plus software.

Rietveld refinement was carried out with two phases present: $\gamma$-austenite $(\mathrm{Fm} \overline{3} \mathrm{~m})$ and $\alpha^{\prime}$-martensite (I4/mmm) (Figure 3 (a)). The phase fraction of retained austenite, $\gamma_{R}$, found was of 4.9 and $2.5 \%$ for alloys $\mathrm{A}$ and $\mathrm{B}$, respectively. The lattice parameters were: $\mathrm{a}_{\gamma}=3.5925, \mathrm{a}_{\alpha}=2.8550$ and $\mathrm{c}_{\alpha}=2.8978$ for alloy $\mathrm{A}$, and $\mathrm{a}_{\gamma}=3.5870, \mathrm{a}_{\alpha}=2.8666$ and $\mathrm{c}_{\alpha}=2.9003$ for alloy B. The tetragonality of the matrix was 1.015 and 1.012 for alloys $\mathrm{A}$ and $\mathrm{B}$ respectively.

The needle specimens were also examined. Etching using $2 \%$ nital revealed a martensitic microstructure (Figure 3 (b)). Hardness averages for Alloys A and B were $812 \pm 4$ and $786 \pm 6 \mathrm{HV} 2$, respectively. Therefore it appears that the austenitisation and quenching processes were carried out adequately. 

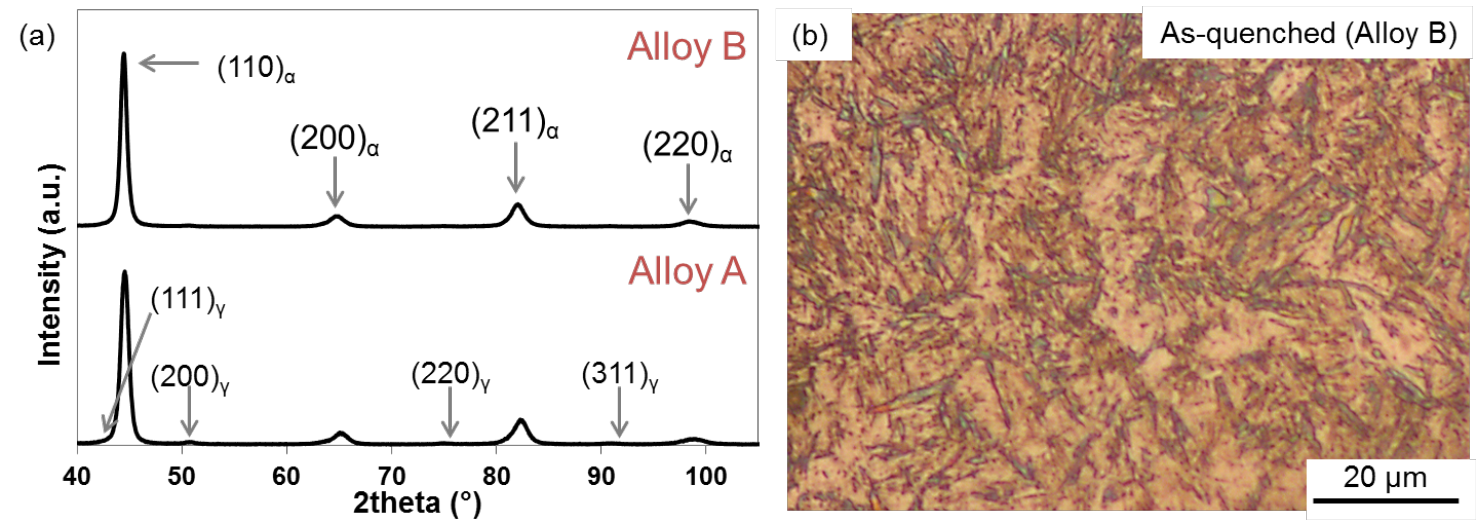

Figure 3: (a) As-quenched XRD pattern for flat-plate specimens and (b) optical microscopy revealing martensitic microstructure for alloy B needle specimen.

\subsection{Model alloy}

Given its relatively simple chemical composition, this ternary system is first assessed in order to become acquainted with the in situ technical aspects. Due to considerable absorption owing to sample thickness, at this stage, synchrotron data has only been limited to qualitative analysis.

\subsubsection{Carbide evolution throughout tempering}

In order to identify the peaks in Figure 4 (a), the following phases have been considered: ferrite $(\operatorname{Im} \overline{3} \mathrm{~m})$, austenite $(\mathrm{Fm} \overline{3} \mathrm{~m})$ epsilon $\left(\mathrm{P}_{3} 22\right)$ and cementite (Pnma), within the 20-30 2theta range. These have been obtained from the FIZ Karlsruhe Inorganic Crystal Structure Database (ICSD) [36].

In literature, $\gamma_{R}$ is seen to decompose from $200-300{ }^{\circ} \mathrm{C}$ in medium-carbon martensitic steels [37]. Given the low volume fraction of $\gamma_{R}$ in the as-quenched condition, it is possible that most of $\gamma_{R}$ decomposed during the isothermal holding at $300{ }^{\circ} \mathrm{C}$, which would explain the absence of the austenite peaks.

Furthermore, $\varepsilon$-carbide peaks are not visible. One possible explanation is that owing 
to its small crystallite size and its low volume fraction, considerable broadening takes place, beyond detection limit. Another possible explanation is that the formation of $\varepsilon$-carbide is supressed, and instead cementite is directly precipitated. Kalish and Cohen [38] stated that in highly dislocated martensite, carbon preferentially segregates into dislocation cores. As tempering progresses, dislocations loose the ability to retain the carbon and cementite is precipitated, skipping the intermediate $\varepsilon$-phase. Following earlier work by the authors [39], 4 days of ageing would have been sufficient for significant microstrucrucal change in the as-quenched state. One further possible explanation is that the sample undergoes $\varepsilon \rightarrow \theta$ during the initial isothermal holding at $300{ }^{\circ} \mathrm{C}$. However, previous TEM characterisation of the model alloy showed that after tempering at $300{ }^{\circ} \mathrm{C}$ for $1800 \mathrm{~s}, \varepsilon$-carbide was obtained [16].

\subsubsection{Thermal gradient estimation}

Figure 4(a) shows the diffraction peaks obtained for Model Alloy. Dilatometry curves revealed that the austenitisation temperature of the alloy, $\mathrm{Ac}_{1}$, was $808.3 \pm 2.0{ }^{\circ} \mathrm{C}$. Given that even when the temperature of the nozzle, $\mathrm{T}$ (nozzle), indicates $900{ }^{\circ} \mathrm{C}$, there is no evidence that the material undergoes ferrite-austenite phase transformation.

Therefore it becomes evident that there is a significant thermal gradient between the sample and nozzle exit. One way of estimating the thermal gradient is by assuming

that the peak shift is caused by thermal expansion of the lattice. Hence, given its peak shift, the "true" temperature difference, $\Delta T_{\text {true }}$, can be estimated from:

$$
\frac{\Delta L}{L}=\alpha_{L} \Delta T_{\text {true }},
$$

where $\Delta L / L$ is the strain caused by lattice expansion, and $\alpha_{L}$ is $11.8 \times 10^{-6} /{ }^{\circ} \mathrm{C}$ [40]. However, in this case, a slight shift of the ferrite peaks also be due to a reduction in 
tetragonality within the matrix phase.

(a)

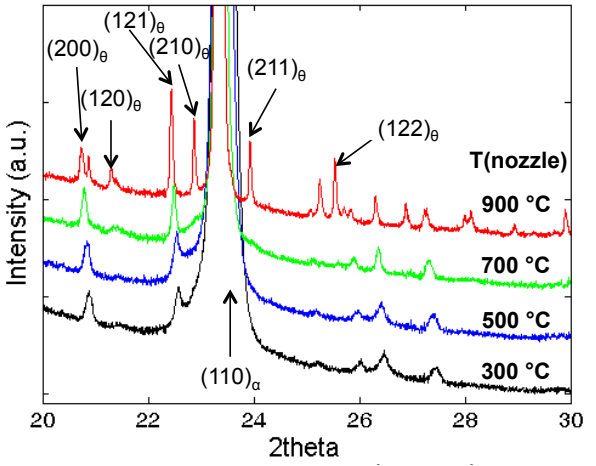

(b)

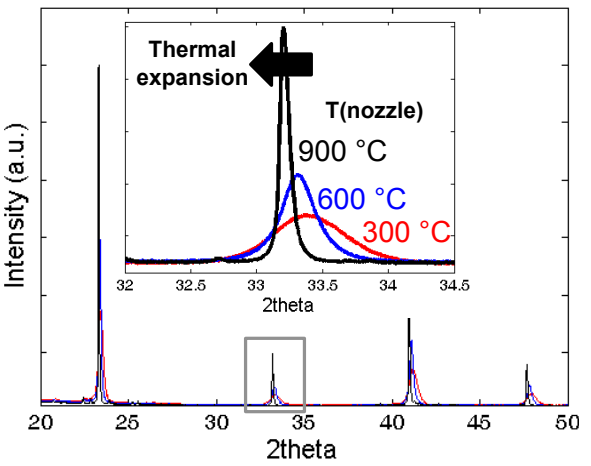

(c)

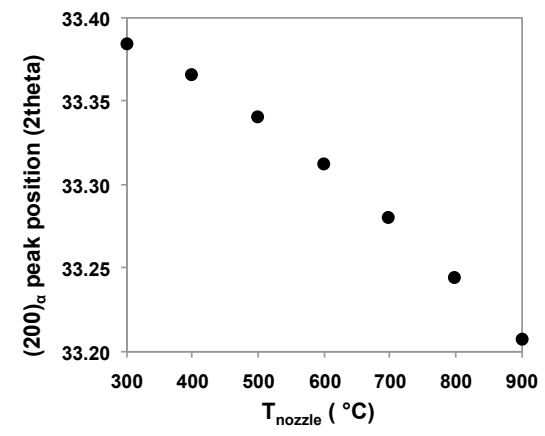

Figure 4: (a) Closed-up view between $20<2 \vartheta<30$ for the in situ tempering of the model alloy, (b) Peak shift due to thermal expansion shown for Model Alloy where the inset shows a magnified view of the (200) ferrite reflection (NB. Temperature indicated refers to that of the nozzle), and (c) (200) peak position at different temperatures.

From Figure 4 (b), and using (10), it is observed that $\Delta T$ (nozzle) of $600{ }^{\circ} \mathrm{C}$ corresponds to $\Delta T_{\text {true }} \approx 447^{\circ} \mathrm{C}$. This implies that the actual tempering was carried out 
until $\approx 750{ }^{\circ} \mathrm{C}$. Although this is still an approximation, it provides a more realistic view of the actual tempering conditions. Therefore, from here onwards, this correction factor will be assumed. Furthermore, it is worth noting that considerable sharpening of the ferrite peaks takes place. Given that peak broadening can also be attributed to the presence of defects in the lattice, e.g. dislocations, it is also possible to relate the evolution of dislocation density in ferrite throughout tempering. This aspect will be explored in future work.

\subsection{Alloys A and B}

\subsubsection{Reference samples}

The diffraction spectra for reference samples prepared by dilatometry are shown in Figure 5 .
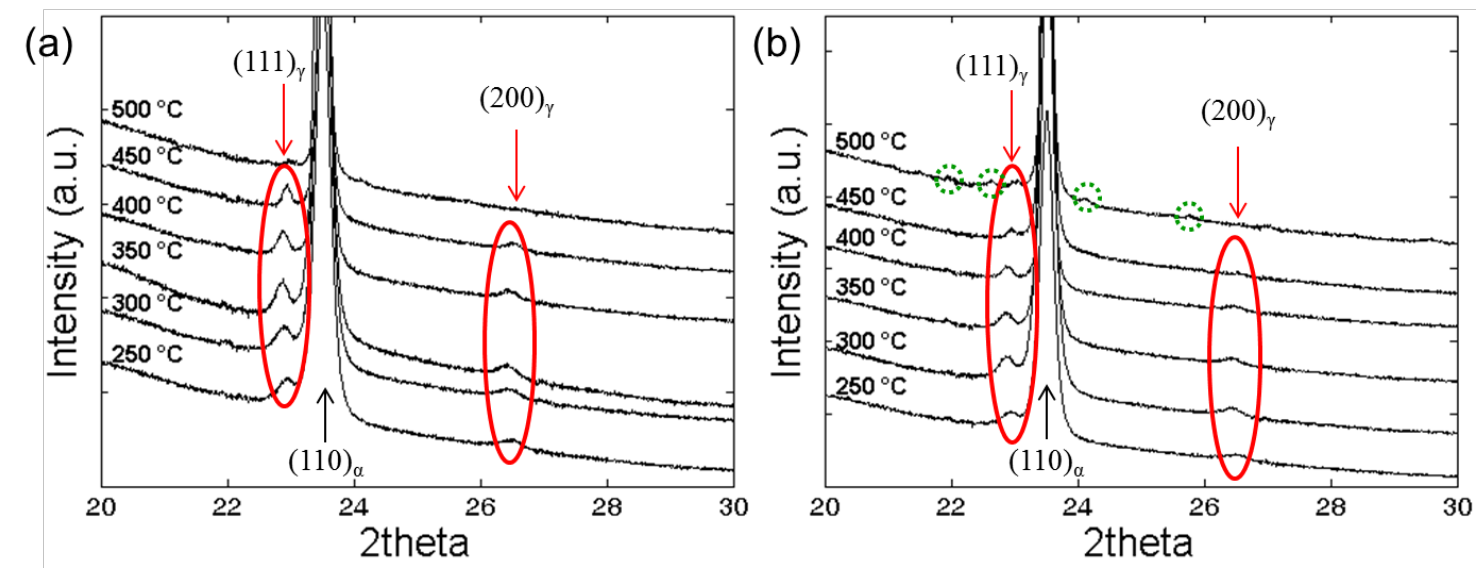

Figure 5: XRD spectra shown for the reference samples for alloys (a) A and (b) B.

Surprisingly, the retained austenite seems to be stable even after $1800 \mathrm{~s}$ at temperatures up to $400{ }^{\circ} \mathrm{C}$ in the lower silicon alloys and $450{ }^{\circ} \mathrm{C}$ in the higher silicon contents. In the case of tempering at $500{ }^{\circ} \mathrm{C}$, carbide peaks (dotted circles in Figure 5 (b)) are stronger in the lower silicon alloy. 


\subsubsection{Cementite growth}
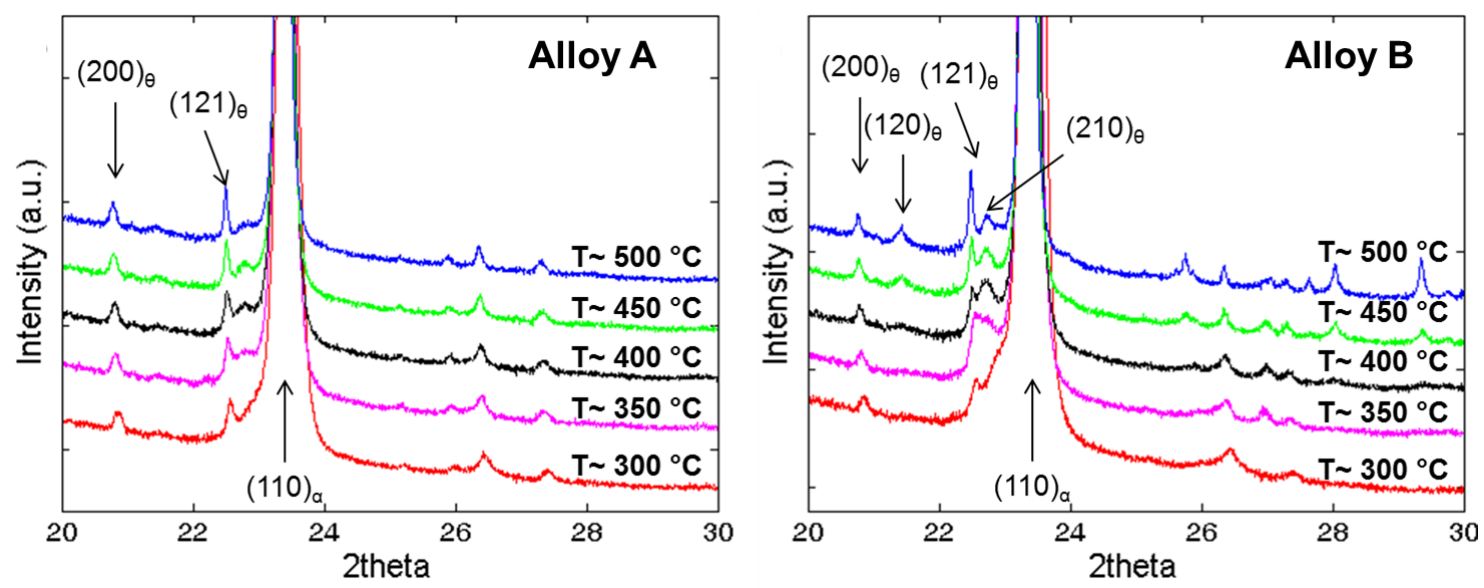

Figure 6: In situ runs for alloys (a) A and (b) B.

Cementite peaks are already present by the time the first measurement had been taken. Although it has not ben possible to follow the early nucleation stage of cementite during synchrotron analysis, it allows the growth stage to be studied. For instance, it is possible to observe is that cementite peaks appear much stronger in the lower silicon alloy (Figure 6 (b)). The relative intensities for the cementite peaks are much stronger in Alloy B than in A, implying faster precipitation rates for the lower silicon case during continuous tempering.

\section{Kinetics}

Previously it was presented by the authors [16] that the $\varepsilon \rightarrow \theta$ carbide transition relies on the partitioning of silicon out of the carbide, specifically at a distance of 1-2 nm, based on the postulate that the nucleation of cementite required a silicon free region in the matrix. Hence the diffusion of silicon in ferrite was used as a criterion for cementite nucleation. However, by considering the formation of cementite under paraequilibrium 
conditions, one must allow silicon to be initially incorporated into the carbide. Past the nucleation stage, it is the growth stage that appears greatly affected by the presence of silicon.

3DAP results presented by Caballero et al. are charted in Figure 7, where it has been observed that the measured silicon content within cementite decreased with increasing tempering temperature. It also reinforces the findings by Reisdorf [9].

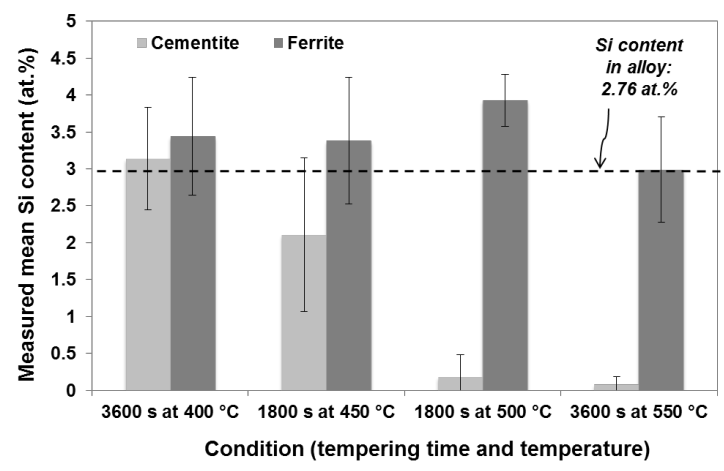

Figure 7: Average silicon content in ferrite and cementite for different tempering conditions, from tabulated data in [41].

When considering cementite formation under paraequilibrium conditions at relatively low temperatures, the diffusion of the substitutional elements is negligible. One can assume that at this stage, only carbon content will be differnet across the matrix/carbide interface, whereas the rest of the elements remain the same. However, at higher temperatures, the trapped silicon within cementite will begin to diffuse out of the carbide, as the carbide tends to equilibrium. Consequently, the rejected silicon buils up a Si-rich layer at the interface [10], illustrated in Figure 8 (a). 


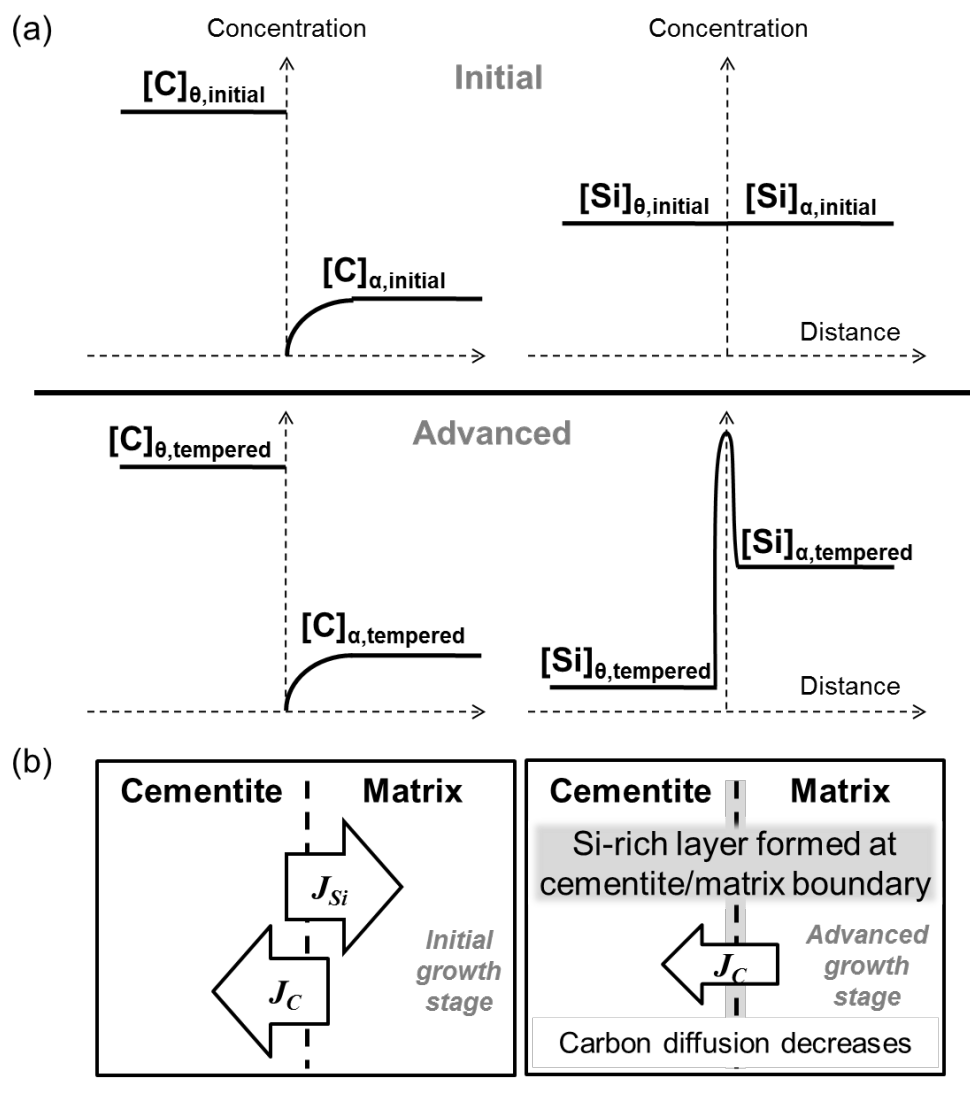

Figure 8: (a) Possible growth mechanism for cementite, and (b) Silicon and carbon content variation throughout tempering, where $J_{C}$ and $J_{S i}$ refer to the carbon and silicon flux across the interface.

For continuous carbide growth, further carbon is needed. However the carbon flux into the carbide across the interface will be reduced due to the Si-rich layer, as illustrated in Figure 8 (b). Therefore the diffusion rate of silicon within cementite is likely to be rate-controlling factor in the growth of carbides. This mechanism has also been hinted by Barrow and Rivera-Díaz-del-Castillo [42]. This agrees well with the carbide growth seen during in situ synchrotron analysis (Figure 6). 


\section{Conclusions}

1. The thermodynamic driving force for cementite nucleation was computed under paraequilibrium conditions. This ensures the incorporation of silicon within the carbide at the nucleation stage.

2. The misfit strain energy combined with the thermodynamic driving force has shown to play a key role on the cementite nucleation in martensite.

3. The occurrence of $\varepsilon$-carbide in tempered martensite lowers the misfit at the carbide/matrix interface, as opposed to when cementite directly occurs.

4. The growth kinetics of cementite is governed by the partitioning of silicon, as the rejected silicon envelopes at the carbide/matrix interface. This would decrease the flux of carbon from the matrix into cementite for further growth, slowing down precipitation.

\section{Acknowledgements}

Authors B. Kim and P.E.J. Rivera are grateful to Prof. A.L. Greer for the provision of laboratory facilities and would like to acknowledge ASCOmetal for financial support. D. San Martín would like to acknowledge the financial support from the Ministerio de Economía y Competitividad (project No. MAT2010-19522). C. Celada is grateful for the financial support received from the Consejo Superior de Investigaciones Científicas (CSIC) in the form of a JAE-predoc grant under the program Junta para la Ampliación de Estudios, co-funded by the European Social Fund. The authors would also like to thank the Diamond Light Source for access to Beamline I11, and the beamline team, especially Prof. Chiu Tang and Dr Paul Adamson for their assistance throughout beamtime, and Dr Julia Parker for the trial runs. In addition, B. Kim is grateful to Dr Howard Stone for the initial help and guidance in planning the synchrotron work and 
Mr Olivier Messe for his contribution in the beamline. The authors are grateful for the synchrotron sample machining by Mr Javier Vara (CENIM).

\section{References}

[1] Allten AG, Payson P. Trans. ASM 1953;45:498-525.

[2] Altstetter AG, Cohen M, Averbach BL. Trans. ASM 1962;55:287-300.

[3] Chang L, Smith GDW, Olson GB. J. Phys. Colloq. 1984;45:397-401.

[4] Delagnes D, Lamesle P, Mathon M, Mebarki N, Levaillant C. Mater. Sci. Eng. A 2005;394:435-444.

[5] Gordine J, Codd I. J. Iron Steel Ins. 1969;207:461-467.

[6] Nam WJ, Choi HC. Mater. Sci. Technol. 1997;13:568-574.

[7] Nam WJ, Choi HC. Mater. Sci. Technol. 1999;15:527-530.

[8] Nam WJ, Lee CS, Ban DY. Mater. Sci. Eng. A 2000;289:8-17.

[9] BG Reisdorf. Trans. AIME 1963;227:1334-1341.

[10] Zhu C, Xiong XY, Cerezo A, Hardwicke R, Krauss G, Smith GDW. Ultramicrosc. 2007;107:808-812.

[11] Miyamoto G, Oh JC, Hono K, Furuhara T, Maki T. Acta Mater. 2007;55:50275038.

[12] Ghosh G, Olson G. Metall. Mater. Trans. A 2001;32:455-467.

[13] Kozeschnik E, Bhadeshia HKDH. Mater. Sci. Technol. 2008;24:343-347. 
[14] Jang JH, Kim IG, Bhadeshia HKDH. Scr. Mater. 2010;63:121-123.

[15] Barrow AT, Kang JH, Rivera-Díaz-del-Castillo PEJ. Acta Mater. 2012;60:28052815.

[16] Kim B, Martín D San, Chao J, Rivera-Díaz-del-Castillo PEJ. in Proocedings of the international conference Materials Science and Technology 2012.

[17] Thompson SP, Parker JE, Potter J, Hill TP, Birt A, Cobb TM. Rev. Scient. Instrum. 2009;80:075107.

[18] VanGenderen MJ, Böttger A, Cernik RJ, Mittemeijer EJ. Metall. Trans. A 1993;24:1965-1973.

[19] VanGenderen MJ, Böttger A, Mittemeijer EJ. Scr. Metall. Mater. 1992;26:883-888.

[20] Delagnes D, Pettinari-Sturmel F, Mathon M, et al. Acta Mater. 2012;60:5877-5888.

[21] Mulholland M, Seidman D, David N. Acta Mater. 2011;59:1881-1897.

[22] Nam WJ, Kim DS, Ahn ST. J. Mater. Sci. 2003;38:3611-3617.

[23] Perez M, Deschamps A. Mater. Sci. Eng. A 2003;360:214-219.

[24] Porter DA, Easterling KE, Sherif MY. Phase transformations in metals and alloys. CRC Press third ed. 2009.

[25] Hillert M. Phase equilibria, phase diagrams and phase transformations. Cambridge University Press 2007.

[26] KTH ThermoCalc. TC Database Guide

[27] Nagakura S. J. Phys. Soc. Jpn. 1959;14:186-195.

[28] Ghosh G, Olson G. Acta Mater. 2002;50:2099-2119. 
[29] Nabarro FRN. Proc. Roy. Soc. Lond. 1940;175:519-538.

[30] Lee SJ, Lee YK. Scr. Mater. 2005;52:973-976.

[31] Ledbetter HM, Reed RP. J. Phys. Chem. Ref. Data 1973;2:531-617.

[32] Onink M, Brakman CM, Tichelaar FD, et al. Scr. Metall. Mater. 1993;29:10111016.

[33] Andrews KW. Acta Metall. 1963;11:939-946.

[34] Murphy S, Whiteman JA. Metall. Trans. 1970;1:843-848.

[35] Thompson SP, Parker JE, Marchal JJ, Potter J, Birt A, Yuan F. J. Synchrotron Radiat. 2011;18:637-648.

[36] FIZ Karlsruhe ICSD, http://www.fiz-karlsruhe.de

[37] Williamson DL, Schupmann RG, Materkowski JP, Krauss G. Metall. Trans. A 1979;10:379-382.

[38] Kalish D, Cohen M. Mater. Sci. Eng. 1970;6:156-166.

[39] Kim B, Celada C, Martín D San, Chao J, Vara J, Rivera-Díaz-del-Castillo PEJ. Scr. Mater. 2013;68:945-948.

[40] ASM Handbook online, http://products.asminternational.org/hbk/index.jsp

[41] Caballero FG, Miller MK, Garcia-Mateo C, Capdevila C, Babu SS. Acta Mater. 2008;56:188-199.

[42] Barrow AT, Rivera-Díaz-del-Castillo PEJ. Acta Mater. 2011;59:7155-7167. 